\title{
BMJ Open Antibiotic prescription among outpatients in a prefecture of Japan, 2012-2013: a retrospective claims database study
}

\author{
Hideki Hashimoto, ${ }^{1}$ Hiroki Matsui, ${ }^{2,3}$ Yusuke Sasabuchi, ${ }^{2}$ Hideo Yasunaga, ${ }^{2,3}$ \\ Kazuhiko Kotani, ${ }^{4}$ Ryozo Nagai, ${ }^{5}$ Shuji Hatakeyama ${ }^{1,6}$
}

To cite: Hashimoto $\mathrm{H}$, Matsui $\mathrm{H}$, Sasabuchi Y, et al. Antibiotic prescription among outpatients in a prefecture of Japan, 20122013: a retrospective claims database study. BMJ Open 2019;9:e026251. doi:10.1136/ bmjopen-2018-026251

- Prepublication history and additional material for this paper are available online. To view these files, please visit the journal online (http://dx.doi. org/10.1136/bmjopen-2018026251).

Received 23 August 2018 Revised 21 February 2019 Accepted 28 February 2019

Check for updates

(c) Author(s) (or their employer(s)) 2019. Re-use permitted under CC BY-NC. No commercial re-use. See rights and permissions. Published by BMJ.

For numbered affiliations see end of article.

Correspondence to Dr Shuji Hatakeyama; shatake-tky@umin.ac.jp

\section{ABSTRACT}

Objectives To investigate oral antibiotic prescribing patterns and identify factors associated with antibiotic prescriptions, with the aim of guiding future interventions to reduce inappropriate prescribing.

Design Retrospective cohort study.

Setting Database of public health insurance claims in Kumamoto prefecture (Japan).

Participants Beneficiaries of the national or late elders' health insurance system between April 2012 and March 2013.

Main outcome measures of the 7770481 outpatient visits, 682822 had a code for antibiotics (860 antibiotic prescriptions per 1000 population). Third-generation cephalosporins (35\%), macrolides (32\%) and quinolones $(21 \%)$ were the most frequently prescribed. Acute respiratory tract infections (ARTIs), including viral upper respiratory infections (URI) (22\%), pharyngitis (18\%), bronchitis (11\%) and sinusitis $(10 \%)$ were the most frequently diagnosed for antibiotic prescribing, followed by gastrointestinal $(9 \%)$, urinary tract $(8 \%)$ and skin, cutaneous and mucosal infections (5\%). Antibiotic prescribing rates for viral URI, pharyngitis, bronchitis, sinusitis and gastrointestinal infections were 35\%, 54\%, $53 \%, 57 \%$ and $30 \%$, respectively. In multivariable analysis for ARTIs and gastrointestinal infections, patient age (1019 years especially), patient sex (male) and facility scale (free-standing clinics or small-scale hospital-based clinics) were associated with increased antibiotic prescribing. Conclusions Broad-spectrum antibiotics constituted $88 \%$ of oral outpatient antibiotic prescriptions. Approximately $70 \%$ of antibiotics were prescribed for ARTIs and gastroenteritis with modest benefit from antibiotic treatment. The quality of antibiotic prescribing needs to be improved. Antimicrobial stewardship interventions should target ARTIs and gastroenteritis, as well as young patients and small-scale institutions.

\section{INTRODUCTION}

There is a growing concern about antimicrobial-resistant bacterial infections. Antimicrobial resistance results in increased healthcare costs, prolonged hospitalisation and death. ${ }^{1-3}$ The WHO launched the global

\section{Strengths and limitations of this study}

- This is the first Japanese study to describe outpatient antibiotic prescription patterns linked to individual diagnosis data, comprehensively, by use of the public health insurance claims database.

- This study included patients $>65$ years of age, who have not typically been included in previous Japanese studies

- The accuracy of the diagnosis has not been validated due to the nature of the administrative claims database.

- There are some unmeasured potential confounding factors such as out-of-hours visits and physician specialty.

action plan to combat the antimicrobial-resistant bacteria in $2015^{4}$ and requested Member States to endorse national action plans within 2 years. The government of Japan launched a national action plan in 2016 in response to the request. ${ }^{5}$

Since antimicrobial use is one of the important factors in the emergence of antimicrobial resistance,${ }^{6}$ it is essential to reduce the inappropriate use of antibiotics. In Japan, a previous sales data-based study revealed that oral antibiotics account for $>90 \%$ of total antibiotic consumption and that broad-spectrum antibiotics (third-generation cephalosporins, macrolides and fluoroquinolones) account for $77 \%$ of oral antibiotic consumption (daily doses defined per 1000 inhabitants per day). ${ }^{7}$ The Japanese national action plan aims to reduce the total antimicrobial use to two-thirds of current use, and the use of oral cephalosporins, quinolones and macrolides to one-half, by 2020. To reduce inappropriate antimicrobial use, it is important to determine the antimicrobial prescribing patterns and factors associated with antibiotic prescription. However, such information 
has been limited in Japan to date. Although a few recent studies ${ }^{8}$ described the prescription patterns for upper respiratory tract infections and bronchitis, the prescription patterns of infections other than acute respiratory tract infections (ARTIs) have not been clarified. In addition, patients $>65$ years of age have not been commonly included in these studies, because these studies relied on data from an employee-based insurance claims database. With the high rate in ageing population in Japan, it is important to describe the prescription patterns in elderly patients.

In this study, we described outpatient oral antibiotic prescribing patterns for all infections and in all ages using the Japanese administrative claims database. Furthermore, we aimed to identify factors associated with antibiotic prescriptions for ARTIs and gastrointestinal infections, the targets of the antimicrobial stewardship guideline formulated by the government of Japan in 2017..$^{10}$

\section{METHODS}

\section{Data sources}

The current population of Japan is approximately 127 million. All citizens are enrolled in a universal health coverage insurance programme provided by the social insurance system (for employees $<75$ years of age), national health insurance system (for self-employed or unemployed people $<75$ years of age) and the late elders' health insurance system (for those aged $\geq 75$ years). In Japan, patients can visit any clinic of their choice. All physicians working at any free-standing or hospital-based clinics can provide primary care and prescribe antibiotics.

We conducted a retrospective analysis using the administrative health insurance claims database of Kumamoto prefecture, situated in the southwestern region of Japan, with a population of about 1.7 million. This database covers approximately 780000 residents of Kumamoto prefecture ( $44 \%$ of the population) who were beneficiaries of the national health insurance system ${ }^{11}$ or the late elders' health insurance system. ${ }^{12}$ The participants in this study may be older than the general population of Japan.

The database is composed of medical and pharmacy claims. It provides monthly information about patient demographics (year and month of birth and sex), diagnoses, date of diagnoses, medical procedures, medications, scale (number of beds) of the medical facility, as well as the identification numbers assigned to each individual, medical facility and dispensing pharmacy. At the end of each month, claims are registered from each medical facility. The diagnoses were recorded by physicians of each medical facility and coded according to the International Classification of Diseases and Related Health Problems, 10th Revision (ICD-10).

\section{Data preparation}

We linked the medical and pharmacy claims on the database using an identification number unique to each patient, medical facility and dispensing pharmacy. We identified all newly diagnosed outpatients, with any infectious diseases, between April 2012 and March 2013. Infectious diseases diagnoses were categorised according to the indication for antibiotic use (online supplementary table S1, available as online supplementary data). This categorization was based on the study by Fleming-Dutra $e t$ al. ${ }^{13}$ Bronchitis and bronchiolitis were divided into two categories based on whether the patients had chronic obstructive pulmonary disease (COPD) as comorbidity or not, because of differing need of treatment with antibiotics. If a patient had multiple infectious diagnoses in 1 month, a single infectious diagnosis, selected in order from group 1 (antibiotics are usually indicated) to group 3 (antibiotics are rarely indicated), and the first-listed diagnosis in alphabetical order of ICD-10 codes in the selected group was included in the analyses (online supplementary table S1).

We also identified all outpatients with any antibiotic prescriptions. Topical, intramuscular and intravenous antibiotics were excluded. Antibiotics were categorised according to the Anatomical Therapeutic Chemical (ATC) classification system (http://www.whocc.no/ atcddd/) as follows: tetracyclines (J01A), penicillins (J01C), first-generation and second-generation cephalosporins (J01DB and J01DC), third-generation cephalosporins (J01DD), sulfonamides and trimethoprim (J01E), macrolides (J01FA), quinolones (J01M) and others (J01B, J01DH, J01DI, J01FF, J01G and J01X). We assumed that third-generation cephalosporins accounted for most of cephalosporins used in Japan; hence, we divided cephalosporins into two groups: first/second-generation and third-generation cephalosporins. Antibiotics were linked to the infectious diagnoses in each patient's claims when both the code of antibiotics and the code of diagnoses were recorded in the same month.

\section{Data analysis}

We calculated the frequency of antibiotic prescription for all visits with infections (according to diagnosis and antibiotic class). For ARTIs (including pharyngitis, sinusitis, bronchitis/bronchiolitis and viral upper respiratory infections [URI]) and gastrointestinal infections, we performed separate multivariable logistic regression analyses to identify the factors associated with antibiotic prescriptions. The variables were as follows: age and sex of patients and scale (number of beds) of the medical facilities. Generalised estimating equations with exchangeable correlation structure were used to account for the clustering of the medical facilities. P values $<0.05$ were considered statistically significant. All statistical analyses were performed with the statistical package R, V.3.5.0 (http://cran.r-project.org).

\section{Patient involvement}

No patients were involved in the development of the research question or the outcome measures, nor were they involved in developing plans for design or 
Table 1 Frequency of oral antibiotic prescriptions by age and antibiotic groups

\begin{tabular}{|c|c|c|c|c|c|}
\hline \multirow{3}{*}{$\begin{array}{l}\text { Antibiotic groups coded by ATC } \\
\text { classification* }\end{array}$} & \multicolumn{5}{|c|}{ Number $(\%)$ of visits with antibiotic prescription } \\
\hline & \multicolumn{5}{|c|}{ Age group, years } \\
\hline & $0-9$ & $10-19$ & $20-64$ & $\geq 65$ & All ages \\
\hline $\begin{array}{l}\text { First/second-generation } \\
\text { cephalosporins }\end{array}$ & $964(0.9)$ & $411(1.0)$ & $2987(1.6)$ & $5719(1.6)$ & $10081(1.5)$ \\
\hline Quinolones & $7286(7.0)$ & $4158(10.2)$ & $48843(25.6)$ & $84848(24.4)$ & $145135(21.3)$ \\
\hline Sulfonamides and trimethoprim & $32(0.0)$ & $53(0.1)$ & $1389(0.7)$ & $4520(1.3)$ & $5994(0.9)$ \\
\hline Tetracyclines & $915(0.9)$ & $1366(3.3)$ & $4366(2.3)$ & $5147(1.5)$ & $11794(1.7)$ \\
\hline Other antibiotics & $6901(6.6)$ & $2021(5.0)$ & $7186(3.8)$ & $7965(2.3)$ & $24073(3.5)$ \\
\hline
\end{tabular}

*Penicillins, J01C; First-generation cephalosporins, J01DB; Second-generation cephalosporins, J01DC; Third-generation cephalosporins, J01DD; Macrolides, J01FA; Quinolones, J01M; Sulfonamides and trimethoprim, J01E; Tetracyclines, J01A; Other antibiotics, J01B, J01DH, J01DI, J01FF, J01G and J01X.

ATC , anatomical therapeutic chemical.

implementation of the study. No patients were asked for advice regarding the interpretation or writing of results. There are no plans to disseminate the study results to the relevant patient community.

\section{RESULTS}

In total, there were 7770481 outpatient visits between April 2012 and March 2013. Antibiotics were prescribed in 682822 visits (860 antibiotic prescriptions per 1000 population). Among these, third-generation cephalosporins were the most frequently prescribed (237372 visits, 35\%), followed by macrolides (215656 visits, 32\%) and quinolones (145135 visits, 21\%). This trend was observed regardless of age group (table 1) and scale of the medical facility (table 2), except for those $<9$ years of age in whom the systemic use of quinolones is not

Table 2 Frequency of oral antibiotic prescriptions by facility scale and antibiotic group*

\begin{tabular}{|c|c|c|c|c|c|}
\hline \multirow[b]{2}{*}{$\begin{array}{l}\text { Antibiotic groups } \\
\text { coded by ATC } \\
\text { classification† }\end{array}$} & \multicolumn{5}{|c|}{ Number (\%) of visits with antibiotic prescription } \\
\hline & $\begin{array}{l}\text { Free-standing } \\
\text { clinic }\end{array}$ & $\begin{array}{l}\text { Small-scale hospital } \\
\text { (<200 beds)-based } \\
\text { clinic }\end{array}$ & $\begin{array}{l}\text { Medium-scale } \\
\text { hospital (200-499 } \\
\text { beds)-based clinic }\end{array}$ & $\begin{array}{l}\text { Large-scale hospital } \\
\text { ( } \geq 500 \text { beds)-based } \\
\text { clinic }\end{array}$ & All facilities \\
\hline Penicillins & $25225(4.8)$ & $3453(4.4)$ & $2968(6.6)$ & 565 (3.9) & $32211(4.8)$ \\
\hline $\begin{array}{l}\text { First/second- } \\
\text { generation } \\
\text { cephalosporins }\end{array}$ & $6755(1.3)$ & $1789(2.3)$ & $1245(2.8)$ & $158(1.1)$ & $9947(1.5)$ \\
\hline $\begin{array}{l}\text { Third-generation } \\
\text { cephalosporins }\end{array}$ & $187928(35.4)$ & $25463(32.4)$ & $15252(33.7)$ & $4139(28.8)$ & $232782(34.8)$ \\
\hline Macrolides & $169980(32.0)$ & 26307 (33.5) & $11319(25.0)$ & $3833(26.7)$ & $211439(31.6)$ \\
\hline Quinolones & $110770(20.9)$ & $17877(22.8)$ & $9992(22.1)$ & $3402(23.7)$ & $142041(21.2)$ \\
\hline $\begin{array}{l}\text { Sulfonamides and } \\
\text { trimethoprim }\end{array}$ & $712(0.1)$ & $1069(1.4)$ & $2234(4.9)$ & $1618(11.3)$ & $5633(0.8)$ \\
\hline All antibiotics & 530916 & 78546 & 45271 & 14353 & 669086 \\
\hline
\end{tabular}

*13 736 patients with antibiotic prescription were excluded due to missing data about facility scale.

†Penicillins, J01C; First-generation cephalosporins, J01DB; Second-generation cephalosporins, J01DC; Third-generation cephalosporins, J01DD; Macrolides, J01FA; Quinolones, J01M; Sulfonamides and trimethoprim, J01E; Tetracyclines, J01A; Other antibiotics, J01B, J01DH, J01DI, J01FF, J01G and J01X.

ATC , anatomical therapeutic chemical. 
recommended. Information about facility scale was available from 669086 out of 682822 visits. Of these, antibiotics were prescribed most frequently at free-standing clinics ( 530916 visits, $79 \%)$, followed by small-scale $(<200$ beds; 78546 visits, 12\%), medium-scale (200-499 beds; 45271 visits, $7 \%$ ) and large-scale ( $\geq 500$ beds; 14353 visits, $2 \%$ ) hospital-based clinics (table 2 ).

We were able to link the individual diagnoses to the antibiotic prescription in 447232 visits (table 3). Of these patients, approximately $60 \%$ of antibiotics were prescribed for ARTIs, including viral URI (96989 visits, $22 \%$ ), pharyngitis (78469 visits, $18 \%$ ), bronchitis without COPD (47248 visits, 11\%) and sinusitis (45456 visits, $10 \%)$. Other than ARTIs, there were frequent antibiotic prescriptions for gastrointestinal infections (41309 visits, $9 \%$ ), urinary tract infections (37674 visits, $8 \%$ ), and skin, cutaneous and mucosal infections (23572 visits, 5\%). The antibiotic prescription rates for viral URI, pharyngitis, bronchitis (without underlying COPD), sinusitis and gastrointestinal infections were 35\% (96 989 out of 274441 visits), $54 \%$ (78 469 out of 146508 visits), $53 \%$ (47 248 out of 89479 visits), $57 \%$ (45 456 out of 80078 visits) and 30\% (41 309 out of 137661 visits), respectively (table 3).

Table 4 shows the results of the logistic regression analysis of antibiotic prescription for ARTIs. Male sex was associated with more antibiotic prescription (adjusted OR, $1.10 ; 95 \%$ CI, 1.08 to 1.11 ). With patients aged $\geq 65$ years as reference, patients aged 10-19 years were more likely to be prescribed antibiotics (adjusted OR, 2.75; 95\% CI, 2.69 to 2.82), followed by patients aged 20-64 years (adjusted OR, 1.92; 95\% CI, 1.89 to 1.94) and patients $<10$ years (adjusted OR, 1.48; 95\% CI, 1.46 to 1.50$)$. Regarding facility scale, with large-scale ( $\geq 500$ beds) hospital-based clinics as reference, free-standing clinics (adjusted OR, 4.24; 95\% CI, 4.03 to 4.45), smallscale (<200 beds) hospital-based clinics (adjusted OR, 2.07; $95 \% \mathrm{CI}, 1.97$ to 2.18 ) and medium-scale (200-499 beds) hospital-based clinics (adjusted OR, 1.71; 95\% CI, 1.62 to 1.80 ) were significantly associated with more frequent antibiotic prescription.

Similar results were shown with the logistic regression analysis for gastrointestinal infections (table 5). Male sex was associated with slightly more antibiotic prescription (adjusted OR, 1.04; 95\% CI, 1.01 to 1.06) than the female sex. Patients aged 10-19 years (adjusted OR, 1.92; 95\% CI, 1.83 to 2.00), 20-64 years (adjusted OR, 1.55; $95 \% \mathrm{CI}, 1.51$ to 1.60 ) and $<10$ years (adjusted OR, 1.76; $95 \% \mathrm{CI}, 1.71$ to 1.82 ) received more antibiotic prescriptions compared with patients aged $\geq 65$ years. With reference to large-scale ( $\geq 500$ beds) hospital-based clinics, free-standing clinics (adjusted OR, 1.88; 95\% CI, 1.68 to $2.10)$ and small-scale ( $<200$ beds) hospital-based clinics (adjusted OR, 1.17; 95\% CI, 1.04 to 1.32) were associated with frequent antibiotic prescription for gastrointestinal infections.

\section{DISCUSSION}

We described oral antibiotic prescription patterns in the outpatient care setting in Japan. To the best of our knowledge, this is the first Japanese study to comprehensively describe antibiotic prescription patterns linked to individual diagnoses data, using the claims database. Broad-spectrum antibiotics consisting of third-generation cephalosporins, macrolides and quinolones accounted for nearly $90 \%$ of antibiotic prescriptions in the primary care settings. Prescription of penicillin was only $5 \%$. This prescription pattern is consistent with the results of an analysis of antibiotic sales data in Japan, in which $77 \%$ of oral antibiotics shipped were broad spectrum. ${ }^{7}$ In contrast, the use of cephalosporins, macrolides and quinolones in the USA and Europe were much lower than in Japan. Hicks et $a l^{14}$ analysed the sales data of oral antibiotics in the USA and showed that cephalosporins, macrolides and quinolones accounted for $48 \%$ of the total oral antibiotics. In their study, penicillin had the largest share of the antibiotics (23\%). Data from the European Surveillance of Antimicrobial Consumption (ESAC) project $^{15}$ also showed that cephalosporins, macrolides and quinolones accounted for about one-third of the total oral antibiotic consumptions in Europe. This study demonstrated a rather high ratio of broad-spectrum to narrow-spectrum oral antibiotics in Japan; therefore, the quality of antibiotic prescribing needs to be improved.

Although quinolones are not recommended for children, quinolones were prescribed as much as penicillins in children aged $0-9$ years in our study. This may be because oral fluoroquinolones such as tosufloxacin are approved for children to treat otitis media and pneumonia in Japan. Since the approval of quinolones in 2010, despite the recommendation to prescribe quinolones carefully for children, many physicians prescribed tosufloxacin to children in expectation of clinical effectiveness.

Among antibiotics linked with individual diagnosis data, $>60 \%$ of antibiotics were prescribed for ARTIs, followed by gastrointestinal infections $(9 \%)$, urinary tract infections $(8 \%)$ and skin, cutaneous and mucosal infections (5\%). Surprisingly, viral URI (common cold) was the most frequent infection associated with antibiotic prescription. In the ambulatory care setting in the USA, antibiotics were prescribed most frequently for acute respiratory conditions $(41 \%-44 \%)$, followed by skin and mucosal conditions $(15 \%-19 \%)$, urinary tract infections $(7 \%-8 \%)$ and gastrointestinal conditions $(5 \%-6 \%) .{ }^{13} 16$ Another study using primary care data in the $\mathrm{UK}^{17}$ demonstrated that $46 \%$ of antibiotics were prescribed for respiratory tract conditions, followed by urogenital tract $(23 \%)$ and skin conditions $(10 \%)$. Only $1 \%$ was prescribed for gastrointestinal conditions. Our study demonstrated a higher proportion of antibiotic prescription for ARTIs (approximately $15 \%$ higher than those in USA or UK) and gastrointestinal infections (approximately $5 \%$ higher) in Japan.

Antibiotics were prescribed for $35 \%$ of viral URI cases and approximately $50 \%-60 \%$ of pharyngitis, bronchitis and sinusitis cases in our study. These prescription rates 


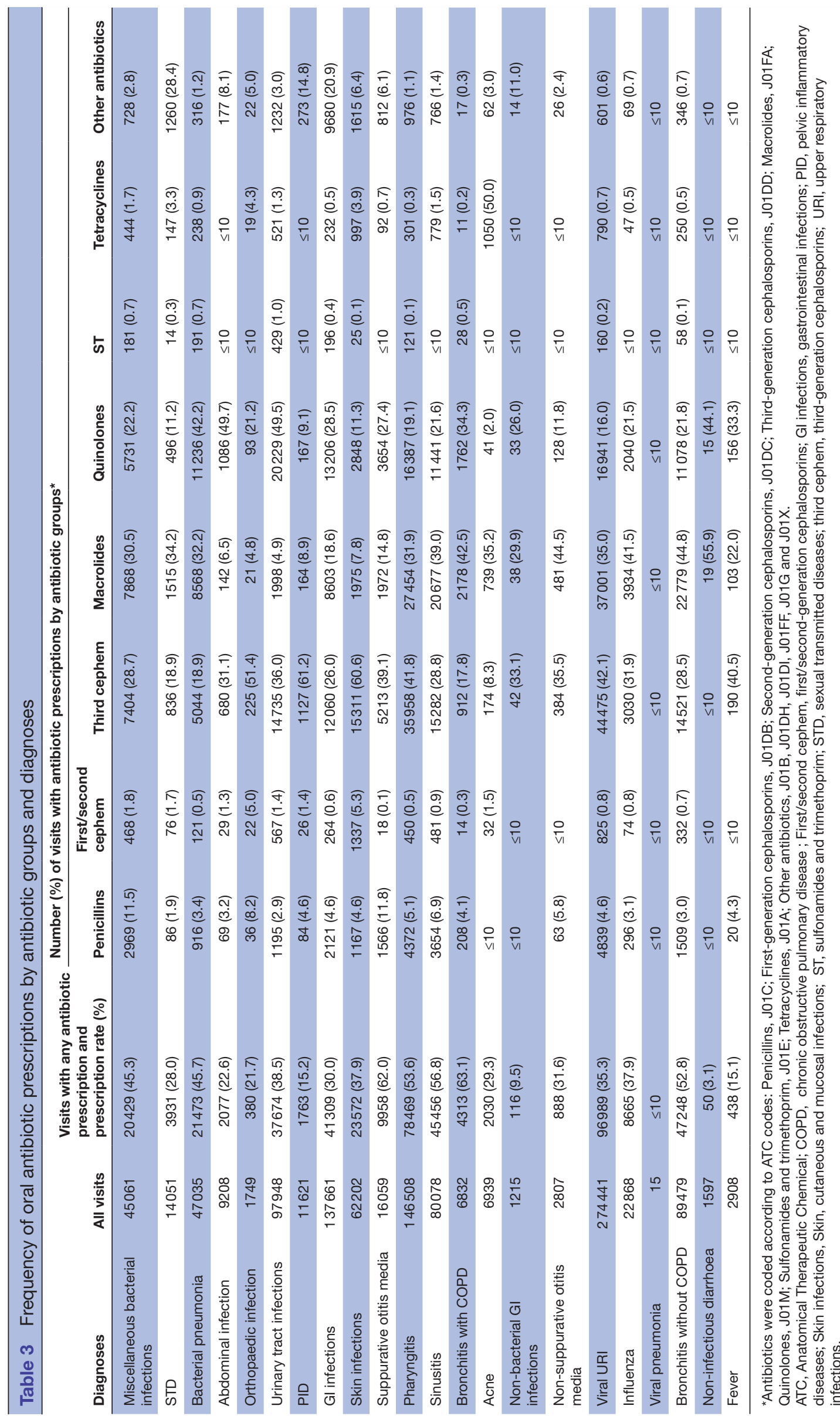


Table 4 Factors associated with antibiotic prescription for acute upper respiratory infections ${ }^{\star}$

\begin{tabular}{|c|c|c|c|}
\hline Characteristics & $\begin{array}{l}\text { Antibiotic prescription, } \\
\mathrm{n}(\%)\end{array}$ & Unadjusted OR $(95 \% \mathrm{Cl})$ & Adjusted OR (95\% Cl) \\
\hline \multicolumn{4}{|l|}{ Patient age } \\
\hline $0-9$ & $44413(50.4)$ & 1.66 (1.64 to 1.69$)$ & $1.48(1.46$ to 1.50$)$ \\
\hline $10-19$ & $20822(65.1)$ & 3.08 (3.00 to 3.15$)$ & 2.75 (2.69 to 2.82 ) \\
\hline $20-64$ & $85952(54.6)$ & 1.98 (1.95 to 2.00$)$ & 1.92 (1.89 to 1.94$)$ \\
\hline$\geq 65$ & $121289(37.9)$ & 1 & 1 \\
\hline \multicolumn{4}{|l|}{ Patient sex } \\
\hline Male & $112643(47.4)$ & $1.13(1.12$ to 1.14$)$ & 1.10 (1.08 to 1.11$)$ \\
\hline Female & $155038(44.4)$ & 1 & 1 \\
\hline \multicolumn{4}{|l|}{ Facility scale } \\
\hline Free-standing clinic & $233078(49.8)$ & 4.48 (4.27 to 4.70$)$ & 4.24 (4.03 to 4.45$)$ \\
\hline Hospital (<200 beds)-based clinic & $23012(30.8)$ & 2.01 (1.91 to 2.11$)$ & 2.07 (1.97 to 2.18$)$ \\
\hline Hospital (200-499 beds)-based clinic & $9327(28.2)$ & 1.77 (1.68 to 1.89$)$ & 1.71 (1.62 to 1.80$)$ \\
\hline Hospital ( $\geq 500$ beds)-based clinic & 2064 (18.2) & 1 & 1 \\
\hline
\end{tabular}

*Acute upper respiratory infections include viral upper respiratory infections, pharyngitis, bronchitis and sinusitis.

were approximately similar to those of a USA study, ${ }^{13}$ which showed a rate of $30 \%$ for viral URI, $62 \%$ for pharyngitis, $65 \%$ for bronchitis and $72 \%$ for sinusitis. Medically, antibiotics are rarely indicated for ARTIs. ${ }^{18}$ Antibiotics have no role in the treatment of either viral URI (common cold) or the majority of acute bronchitis cases, which are generally caused by viral infection. Only a minority of patients with bronchitis $(<10 \%)$, for example, patients who have underlying COPD or whooping cough, may derive any benefit from antibiotic treatment. With pharyngitis, antibiotics are mainly indicated only for streptococcal pharyngitis, which accounts for $5 \%-15 \%$ of pharyngitis in adults and 20\%-30\% in children. ${ }^{19} 20$

The antibiotic prescription rate for gastrointestinal infections was three times higher than the rate reported in the USA (30\% vs $10 \%) \cdot{ }^{13}$ As most acute gastroenteritis is self-limiting, the Japanese national guideline recommends the non-usage of antibiotics for gastroenteritis unless symptoms are severe. ${ }^{10}$ Based on our study, approximately $70 \%$ of oral antibiotics are prescribed for ARTIs or acute gastroenteritis; however, most $(>80 \%)$ did not require antibiotics. Therefore, there is a need for suitable targets to reduce unnecessary antibiotic use in accordance with antimicrobial stewardship programme. Previous studies from the $\mathrm{UK}^{21} 22$ analysed reasons for antibiotic prescribing for sore throats and assessed that patient demand for antibiotics and physician pressure to meet patient demand are associated with antibiotic prescription. In addition, we suppose that physicians frequently prescribe antibiotics for URI as prophylaxis

Table 5 Factors associated with antibiotic prescription for gastrointestinal infections

\begin{tabular}{llll}
\hline Characteristics & $\begin{array}{l}\text { Antibiotic } \\
\text { prescription, } \mathbf{n}(\%)\end{array}$ & Unadjusted OR (95\% Cl) & Adjusted OR (95\% Cl) \\
\hline $\begin{array}{l}\text { Patient age } \\
0-9\end{array}$ & $10809(37.0)$ & $1.92(1.86$ to 1.98$)$ & $1.76(1.71$ to 1.82$)$ \\
\hline $10-19$ & $4395(38.7)$ & $2.07(1.98$ to 2.16$)$ & $1.92(1.83$ to 2.00$)$ \\
\hline $20-64$ & $12310(32.4)$ & $1.57(1.53$ to 1.61$)$ & $1.55(1.51$ to 1.60$)$ \\
\hline$\geq 65$ & $13795(23.4)$ & 1 & 1 \\
\hline Patient sex & & & $1.04(1.01$ to 1.06$)$ \\
\hline Male & $18547(30.9)$ & $1.09(1.06$ to 1.12$)$ & 1 \\
\hline Female & $21831(29.1)$ & 1 & $1.88(1.68$ to 2.10$)$ \\
\hline $\begin{array}{l}\text { Facility type } \\
\text { Free-standing clinic }\end{array}$ & $33712(32.9)$ & $2.03(1.82$ to 2.27$)$ & $1.17(1.04$ to 1.32$)$ \\
\hline Hospital $(<200$ beds)-based clinic & $4056(21.7)$ & $1.15(1.02$ to 1.29$)$ & $0.93(0.82$ to 1.05$)$ \\
\hline Hospital $(200-499$ beds)-based clinic & $2214(18.9)$ & $0.97(0.86$ to 1.09$)$ & 1 \\
\hline Hospital $(\geq 500$ beds)-based clinic & $396(19.4)$ & 1 & \\
\hline
\end{tabular}


for complicating secondary bacterial infections. Previous qualitative studies identified that additional factors associated with antibiotic prescription included diagnostic uncertainty, unawareness of guidelines, time pressure at work, and patient expectations regarding antibiotics. ${ }^{23-25}$

As for antibiotic prescription for ARTIs and gastrointestinal infections, most antibiotics prescribed were broad spectrum. For example, quinolones accounted for $15 \%-35 \%$ of the antibiotics prescribed for ARTIs in this study, although the proportion of quinolones to whole antibiotics prescribed for ARTIs should be $<5 \%$ according to the ESAC disease-specific quality indicators. ${ }^{26}$ Accordingly, the quality of antibiotic prescribing should be improved.

The logistic regression analyses revealed several factors associated with antibiotic prescriptions for ARTIs and gastrointestinal infections. The smaller the facility scale, the higher the odds of antibiotic prescribing. Recent studies from $\operatorname{Japan}^{8}$ and Taiwan ${ }^{27}$ have found similar results. As family practitioners, paediatricians, and internists usually prescribe a high number of antibiotic courses, ${ }^{14}$ greater adherence to treatment guidelines among physicians in these specialties is particularly important. It has also been reported that mid-career or late-career stage physicians (because the effect of training received during medical education might have reduced after this long time) were more likely to prescribe antibiotics for non-bacterial acute URI. ${ }^{28}$

Patient age was another factor associated with antibiotic prescription. In this study, antibiotic prescription rates for ARTIs and gastrointestinal infections were highest in patients aged 10-19 years, followed by patients aged 20-64 years (ARTIs) or 0-9 years (gastrointestinal infections). A previous study concerning Dutch primary care showed similar results of antibiotic overprescribing for ARTIs in patients aged 31-65 years (ie, not in children or the elderly). ${ }^{29}$ As adolescents and young adults generally pose a much lower risk of disease complications than young children or elderly individuals, antimicrobial stewardship should focus on these age groups of patients. In this study, male sex was also associated with increased antibiotic prescribing. Although a patient sex difference was observed in another study, the results differed; female patients were more likely to have high prescribing in the USA. ${ }^{14}$ The reason for patient age and sex difference in antibiotic prescribing remains to be clarified. Patient sex and age-standardised antibiotic prescription rates need to be assessed in Japan for effective intervention.

Our study has several limitations. First, our results do not represent the entire antibiotic prescription pattern in Japan because the claims database used in this study was composed of claims in only one prefecture. Geographical diversity in antibiotic prescribing may be present, as observed in the previous study from the USA. ${ }^{14}$ Second, since we used an administrative claims database, the accuracy of the diagnosis was not validated. In addition, we could not link diagnosis and antibiotic prescriptions on a one-to-one level when patients had multiple infectious diagnoses. Third, there may be other potential confounding factors that were not included in this study. For example, information on out-of-hours visits, ${ }^{8}$ non-specialty physicians ${ }^{82730}$ and patient's low per capita income or low education, ${ }^{14}$ which have been reported as potential factors associated with inappropriate antibiotics prescribing, could not be extracted from the claims database in this study. Fourth, only $65 \%$ of antibiotic prescriptions were linked to infectious disease visits. This may be partly because we could not capture the information concerning follow-up visits when patients had multiple visits for a single infection (antibiotics were linked to the infectious diagnoses only when they were prescribed at the first visit of an illness episode). In addition, approximately $3 \%-5 \%$ of medical claims that included diagnostic codes and $0.1 \%$ of pharmacy claims that included prescription (medication) codes were registered in non-digital format. As non-digital insurance claims were not included in our database, $3 \%-5 \%$ of antibiotic prescriptions were not linked to diagnoses. Therefore, inappropriate antibiotic prescription might be underestimated rather than overestimated.

In conclusion, this Japanese study demonstrated that third-generation cephalosporins, macrolides and quinolones accounted for $88 \%$ of oral antibiotic prescription. Approximately $60 \%$ of antibiotic prescription was provided for ARTIs, with viral URI and pharyngitis being the two ARTI diagnoses with the largest antibiotic prescriptions. Gastrointestinal infections were the second most common diagnosis for antibiotic prescribing. The scale of the facilities (clinic or small-scale hospital) and patient age (adolescents and young adults) were factors associated with antibiotic overprescription. Antimicrobial stewardship interventions should focus on targeting antibiotic prescribing for these infectious diagnoses, patients and institutions. Further nationwide studies are needed to support our data, and longitudinal studies using medical claims data are needed to evaluate the effectiveness of antimicrobial stewardship.

\section{Author affiliations}

${ }^{1}$ Division of General Internal Medicine, Jichi Medical University Hospital, Shimotsuke, Tochigi, Japan

${ }^{2}$ Data Science Center, Jichi Medical University, Shimotsuke, Tochigi, Japan ${ }^{3}$ Department of Clinical Epidemiology and Health Economics, School of Public Health, University of Tokyo, Tokyo, Japan

${ }^{4}$ Division of Community and Family Medicine, Jichi Medical University, Shimotsuke, Tochigi, Japan

${ }^{5}$ President, Jichi Medical University, Shimotsuke, Tochigi, Japan

${ }^{6}$ Division of Infectious Diseases, Jichi Medical University Hospital, Shimotsuke, Tochigi, Japan

Contributors $\mathrm{HH}$ and SH conceived the study, interpreted the data and results and drafted the manuscript. HH, HM, YS and HY collected, organised, analysed the data and performed statistical analyses. KK and RN conceived the study and collected and interpreted the data. All authors critically revised the manuscript for intellectual content. All authors read and approved the final manuscript.

Funding This work was funded by ImPACT Program of Council for Science, Technology and Innovation (Cabinet Office, Government of Japan) and by MEXT KAKENHI, Grant Number 16K09254.

Competing interests None declared. 
Patient consent for publication Not required.

Ethics approval This study was approved by the Ethics Committee of the Jichi Medical University (Number 17-002).

Provenance and peer review Not commissioned; externally peer reviewed.

Data sharing statement № additional data available.

Open access This is an open access article distributed in accordance with the Creative Commons Attribution Non Commercial (CC BY-NC 4.0) license, which permits others to distribute, remix, adapt, build upon this work non-commercially, and license their derivative works on different terms, provided the original work is properly cited, appropriate credit is given, any changes made indicated, and the use is non-commercial. See: http://creativecommons.org/licenses/by-nc/4.0/.

\section{REFERENCES}

1. de Kraker ME, Wolkewitz M, Davey PG, et al. Clinical impact of antimicrobial resistance in European hospitals: excess mortality and length of hospital stay related to methicillin-resistant Staphylococcus aureus bloodstream infections. Antimicrob Agents Chemother 2011;55:1598-605

2. Stewardson AJ, Allignol A, Beyersmann J, et al. The health and economic burden of bloodstream infections caused by antimicrobial-susceptible and non-susceptible Enterobacteriaceae and Staphylococcus aureus in European hospitals, 2010 and 2011: a multicentre retrospective cohort study. Euro Surveill 2016;21:pii=30319.

3. Ammerlaan HS, Harbarth S, Buiting AG, et al. Secular trends in nosocomial bloodstream infections: antibiotic-resistant bacteria increase the total burden of infection. Clin Infect Dis 2013;56:798-805.

4. World Health Organization. Global action plan on antimicrobial resistance. http://apps.who.int/iris/bitstream/10665/193736/1/ 9789241509763_eng.pdf?ua=1 (Accessed 3 Aug 2018).

5. The Government of Japan. National Action Plan on Antimicrobia Resistance (AMR) 2016-2020. https://www.mhlw.go.jp/file/06Seisakujouhou-10900000-Kenkoukyoku/0000138942.pdf (Accessed 3 Aug 2018)

6. Tacconelli E. Antimicrobial use: risk driver of multidrug resistant microorganisms in healthcare settings. Curr Opin Infect Dis 2009;22:352-8.

7. Muraki Y, Yagi T, Tsuji Y, et al. Japanese antimicrobial consumption surveillance: first report on oral and parenteral antimicrobial consumption in Japan (2009-2013). J Glob Antimicrob Resist 2016;7:19-23.

8. Yoshida S, Takeuchi M, Kawakami K. Prescription of antibiotics to pre-school children from 2005 to 2014 in Japan: a retrospective claims database study. J Public Health 2018;40:397-403.

9. Higashi T, Fukuhara S. Antibiotic prescriptions for upper respiratory tract infection in Japan. Intern Med 2009;48:1369-75.

10. The Government of Japan, Ministry of Health, Labour and Welfare. Manual of Antimicrobial Stewardship. 1st edn, 2018.

11. Kumamoto prefectural government. Kumamoto National Health Insurance business situation report. 2012 http://www.pref. kumamoto.jp.e.qp.hp.transer.com/kiji_2735.html (Accessed 3 Aug 2018).

12. Kumamoto prefectural government. The situation such as Kumamoto elderly aged 75 or over medical expenses. http://www.pref. kumamoto.jp.e.qp.hp.transer.com/kiji_13777.html (Accessed 3 Aug 2018).
13. Fleming-Dutra KE, Hersh AL, Shapiro DJ, et al. Prevalence of Inappropriate Antibiotic Prescriptions Among US Ambulatory Care Visits, 2010-2011. JAMA 2016;315:1864-73.

14. Hicks LA, Bartoces MG, Roberts RM, et al. US outpatient antibiotic prescribing variation according to geography, patient population, and provider specialty in 2011. Clin Infect Dis 2015;60:1308-16.

15. ESAC-Net surveillance data. Surveillance of antimicrobial consumption in Europe. http://ecdc.europa.eu/en/publications/ Publications/antimicrobial-consumption-europe-esac-net-2012.pdf (Accessed 3 Aug 2018).

16. Shapiro DJ, Hicks LA, Pavia AT, et al. Antibiotic prescribing for adults in ambulatory care in the USA, 2007-09. J Antimicrob Chemother 2014;69:234-40.

17. Dolk FCK, Pouwels KB, Smith DRM, et al. Antibiotics in primary care in England: which antibiotics are prescribed and for which conditions? J Antimicrob Chemother 2018;73:ii2-ii10.

18. Harris AM, Hicks LA, Qaseem A. High Value Care Task Force of the American College of Physicians and for the Centers for Disease Control and Prevention. Appropriate Antibiotic Use for Acute Respiratory Tract Infection in Adults: advice for high-value care from the American College of Physicians and the Centers for Disease Control and Prevention. Ann Intern Med 2016;164:425-34.

19. Bisno AL. Acute pharyngitis: etiology and diagnosis. Pediatrics 1996;97:949-54.

20. Ebell $\mathrm{MH}, \mathrm{Smith} \mathrm{MA}$, Barry $\mathrm{HC}$, et al. The rational clinical examination. Does this patient have strep throat? JAMA 2000;284:2912-8.

21. Butler CC, Rollnick S, Pill R, et al. Understanding the culture of prescribing: qualitative study of general practitioners' and patients ' perceptions of antibiotics for sore throats. BMJ 1998;317:637-42.

22. Kumar S, Little P, Britten N. Why do general practitioners prescribe antibiotics for sore throat? Grounded theory interview study. BMJ 2003;326:138.

23. Brookes-Howell L, Hood K, Cooper L, et al. Understanding variation in primary medical care: a nine-country qualitative study of clinicians' accounts of the non-clinical factors that shape antibiotic prescribing decisions for lower respiratory tract infection. BMJ Open 2012;2:e000796.

24. Tonkin-Crine S, Yardley L, Little P. Antibiotic prescribing for acute respiratory tract infections in primary care: a systematic review and meta-ethnography. J Antimicrob Chemother 2011;66:2215-23.

25. O'Connor R, O'Doherty J, O'Regan A, et al. Antibiotic use for acute respiratory tract infections (ARTI) in primary care; what factors affect prescribing and why is it important? A narrative review. Ir J Med Sci 2018;187:969-86.

26. Adriaenssens N, Coenen S, Tonkin-Crine S, et al. European Surveillance of Antimicrobial Consumption (ESAC): disease-specific quality indicators for outpatient antibiotic prescribing. BMJ Qual Saf 2011;20:764-72.

27. Lee ML, Cho CY, Hsu CL, et al. Recent trends in antibiotic prescriptions for acute respiratory tract infections in pediatric ambulatory care in Taiwan, 2000-2009: A nationwide populationbased study. J Microbiol Immunol Infect 2016;49:554-60.

28. Silverman M, Povitz M, Sontrop JM, et al. Antibiotic prescribing for nonbacterial acute upper respiratory infections in elderly persons. Ann Intern Med 2017;166:765-74.

29. Akkerman AE, van der Wouden JC, Kuyvenhoven MM, et al. Antibiotic prescribing for respiratory tract infections in Dutch primary care in relation to patient age and clinical entities. J Antimicrob Chemother 2004;54:1116-21.

30. Schmidt ML, Spencer MD, Davidson LE. Patient, Provider, and Practice Characteristics Associated with Inappropriate Antimicrobial Prescribing in Ambulatory Practices. Infect Control Hosp Epidemiol 2018;39:307-15. 